\title{
An Econometric Analysis Of Aging And Alumni/ae Altruism
}

Donald N. Steinnes, (E-mail: dsteinne@d.umn.edu), University of Minnesota, Duluth

\begin{abstract}
While many have studied the motivations for altruism, this paper analyzes the link between aging and alumni/ae giving and, in particular, the changes in donations that are associated with retirement. An econometric methodology is provided that can be used to predict changes in giving based on the aging process. The empirical results, based on the giving of several classes of a small liberal arts college, demonstrate that giving variations (between classes) can be largely explained by age/retirement variables. In addition, possible cohort effects are introduced by adding variables pertaining to the economic conditions for the year in which a class graduated. It is found that starting out (graduating) in poor economic conditions will curtail giving throughout one's life.
\end{abstract}

\section{Introduction}

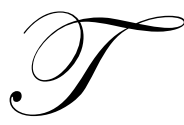

he virtues of charity have been extolled in many societies by a variety of leaders, both religious and political. In America, altruism has been seen as a solution for both moral and economic problems (e.g., George Bush's reference to "A 1,000 Points of Light"). While the beneficial consequences of charity are well recognized, the determinants of charity are much less understood. Some religious organizations require that donations be made as a part of membership (e.g., tithing), but in most instances contributions to charitable organizations are made voluntarily.

An individual's motivation for making contributions to a particular charitable or non-profit organization will no doubt have a deep psychological basis, including one's affinity to the organization. Such allegiances may stem from a common identity (e.g., religious, ethnic, or racial), a common set of beliefs (e.g., on the environment, education or philosophy), or a common experience (e.g., military service, college or hunting). The strength of these connections may well determine if, and how much, donors are willing to give to a charitable or non-profit organization.

Demographics may also play a role in determining donations. In particular, aging will change both income and expenditures for households in predictable ways. During the first years in the workforce, income is relatively low and expenditures are high. Later, income rises and expenditures decline as one retires. As retirement continues, income may decline while expenditures (e.g., medical) rise. As a result, charitable contributions may decrease. In addition, other social characteristics, like marital status and children, my influence donations.

This paper will provide a statistical basis for analyzing the impact of aging on altruism. In addition, it will consider a particular way in which economics plays a role in the determination of donations. For economists, the most obvious determinant would be price, or the law of demand. That is, people will buy more of a product (or donate more) if the price is lower. In the case of charitable contributions, the price would be what it really costs a donor to make a contribution. For example, some employers match employee contributions (e.g., to colleges and universities) and so the cost of a $\$ 1$ donations for such an employee donor would only be $\$ .50$. More important would be the tax implications of donations, many of which are deductible. Depending on one's federal tax bracket, this could reduce the effective price by as much as $39.6 \%$. To study the influence of price on the quantity of

Readers with comments or questions are encouraged to contact the author via email. 
donations, or the price elasticity, would require detailed data on contributions for households in a variety of tax brackets. Unfortunately, the information available for this paper is aggregated and so direct determination of price will not be possible.

Likewise, information is not available directly regarding income, which economists would expect to have a positive influence on donations if they are normal goods (i.e., people buy more (donate) more when their income rises). In addition to income, one might expect other factors to shift the demand for donations (e.g., changes in wealth and expectations). Finally, the demand might be increased by advertising/fund-raising campaigns on the part of charitable organizations.

From the standpoint of a charitable organization, the most interesting research might be to investigate the effectiveness of alternative strategies (e.g., pleas or prizes) in increasing donations. Such an analysis might also include determining the profile of a likely donor and the estimated contribution for different donors (e.g., Britto and Oliver, 1986; and Taylor and Martin, 1995). If one were to analyze a cross-section of comparable organizations (e.g., colleges or universities) it might be possible to ascertain the importance or institutional differences in terms of fund-raising.

This paper, however, will focus on one institution, a small liberal arts college, and the alumni/ae giving for one year (1997). Moreover, the data available are aggregated by classes (i.e., year of graduation) and so individual household socio-economic characteristics will not be considered. The only demographic information known is the age of the class (it will be assumed that all classes graduated at age 22). The effects of advertising or fund-raising campaigns are held constant in that the data are for a single institution in a single year.

One focus of the paper will be on the differences in contributions related to the age of the class. In particular, changes (in giving) that occur late in life (after 65) will be studied. These demographic patterns (over life) are quite strong and explain much of the variation in giving for different classes (cohorts). One consequence, from a policy perspective, is that donations are almost entirely predictable over the course of a person's life and, therefore, fund-raising campaigns may have limited impact.

Aside from finding the link between altruism and aging, the other contribution of the paper will be to analyze if economic conditions in the year a class graduated have any influence on the extent to which the class contributes to the alumni/ae fund in 1997. As will be explained, these variables also serve to control for possible cohort effects in the data. The results will show that adverse economic conditions (e.g., high unemployment) at the time of graduation do, in fact, decrease giving, even years later. This suggests there is a certain economic determinism to one's life that is reflected in one's willingness and/or ability to make contributions. When taken together with the importance of age, the estimation results suggest that giving is largely preordained (at the time of graduation), at least for the alumni/ae of the college studied.

\section{Methodology}

In order to analyze the linkage between aging/retirement and alumni/ae altruism, an econometric model will be formulated, based on the aggregated nature of the data available, and estimated on the basis of 1997 contributions, by class, to a small liberal arts college (St. Olaf College, Northfield, Minnesota). Before specifying variables in the model, it is useful to consider alternative modeling approaches and studies of alumni/ae altruism that have been done in the past. While some have used micro/household data (e.g., Bruggink and Siddiqui, 1995; Lindahl and Winship, 1992; Okunade, Wunnava, and Walsh, 1994; and Okunade, 1996), other studies of alumni/ae giving have been based on aggregated data. Most aggregated is a study (Bristol, 1991), which develops a model for all U.S. alumni/ae donations, based on annual time series data from 1951-90, and uses it to forecast future giving (to all U.S. colleges and universities). The model demonstrates that stock market fluctuations play a large part in year-toyear variations in giving and that the growth in alumni/ae portend substantial increases in alumni/ae giving in the future.

However, most aggregated studies (e.g., Bristol, 1990; Grant and Lindauer; 1986; and Willemain, Goyal, 
Van Deven, and Thukral, 1994) focus on donations for a single school and aggregate the information by class, or year of graduation, as will this paper. Some of these studies also consider donations for different years, while this paper will not. The approach often taken when class year/donation year data are pooled is to introduce dummy variables for each class year and for each donation year. The result is rather complicated and not well suited for forecasting purposes. This is particularly true for the donation year component since it may be influenced by the stock market variations (see Bristol, 1991), which are very difficult to forecast. Therefore, this paper will avoid the potential problems in explaining/forecasting year-to-year changes in donations by analyzing the donations for a single year, 1997.

Instead, the focus will be on explaining differences in donations for various classes. In so doing, this paper will recognize that variations may be the result of the class aging and/or the result of cohort differences in classes. That is, the class of 1930 at age 60 may donate differently than the class of 1960 will when they are 60 for reasons inherent to the class, or cohort. Put another way, these differences are not the result of the year when the class turns 60 (e.g., stock market differences between 1988 when the class of 1930 turns 60 and 2018 when the class of 1960 turns 60) but are differences that are with the classes from their birth (graduation).

Most of the aggregated studies which use different classes as observations, as this paper will, have used multiple regression analysis to estimate a model(s) to explain variations in donations between the classes. Specification of the dependent variable, donations, can be done in different ways. One way would be to use total dollar donations (TOTDON) for the class as the dependent variable. More often, total dollar donations are specified as the product of two dependent variables, percentage of class that donates (PCDONOR) and average dollar donation (AVGDON). Then separate equations are estimated for each dependent variable. The same approach will be taken in this paper and it will be shown that the statistical results are much better than if a single equation is estimated with total dollar donations (TOTDON) as the dependent variable.

While the number of donors for each class, which is the numerator in PCDONOR, is defined the same way in all aggregated studies, including this one, the denominator of PCDONOR can be specified differently. For example, Bristol (1990) uses as the denominator the number of graduates (for each class), which will not vary as the class ages. Hence, the donation rate (PCDONOR) must fall as mortality takes its toll on the class. The consequence of this specification is that one can misinterpret the propensity of older people to donate. To explain, if, in fact, alumni/ae have a greater tendency donate as they get older this may not be observed if the number of graduates is used in the denominator of PCDONOR. Since this paper is centered on the linkage between aging and altruism, a decision has been made to use as the denominator for PCDONOR the number of alumni/ae of record (in 1997). Unlike the number of graduates, which is a constant over time, the number of alumni/ae of record is a current estimate of the number of living alumni/ae for each class. This number shows decline over the years (for a given class), especially for the oldest classes, and, therefore, it is assumed that most of the attrition is the result of mortality rather than lost addresses. The advantage of using number of alumni/ae of record is that PCDONOR can be analyzed without having the influence (negative) of mortality interfere with establishing the relationship between PCDONOR and aging.

The independent, or explanatory, variables in the model(s) have been chosen based on those found to be effective in past studies and selecting variables that would facilitate forecasting (i.e., independent variables whose values would be known with certainty for future years). It has been well established (e.g., Bristol, 1990; Grant and Lindauer, 1986; and Willemain, Goyal, Van Deven and Thukral, 1994) that reunions influence donations. Consequently, this paper uses a dummy variable, REUNION, which is 1 if a class had their 25th or 50th reunion in 1997 and it is anticipated it will have a positive influence on donations (i.e., either PCDONOR or AVGDON). Alternatively, the model(s) are estimated using moving averages (5-year) for the dependent variables to control for the influence of 5-year reunions.

Most important is the way in which age (AGE) is introduced into the model. Previous studies have used age in complex ways but primarily for statistical reasons, rather than on the basis of an aging process. For example, Bristol (1990) estimates eighth degree polynomials for the two dependent variables (i.e., PCDONOR and AVGDON) while Willemain, Goyal, VanDeven, and Thukral (1994) use 90 dummy variables, one for each class in their data set. While statistically effective, these models do not provide an a priori rationale for the age pattern detected 
in the estimation process. This paper, on the other hand, will propose a relationship between aging and altruism and then specify independent variables that can be used to test the proposed relationship. After graduation age may have a fairly simple relation to altruism based on the economic theory of consumption. That is, altruism will increase as graduate's age and earn more money in their career (i.e., assuming altruism is a normal good).

However, it is anticipated that when one retires the pattern of giving may be altered, in part because one's income may change. Also, employees who gave donations matched by their employer would find that the price of donating had gone up in retirement, assuming that former employers will cease to match donations for retired employees. This, too, would suggest that donations would fall after retirement. Therefore, this paper will treat retirement as an event in one's life that may change the relationship between aging and altruism. To statistically consider the possible influence of retirement, alternative independent variables will be specified. In so doing it is assumed that all classes graduated at age 22 and retired at age 65 . The assumption of that all classes graduated at age 22 is probably more true for the small liberal arts college studied that for public universities which have seen the average years in college grow over the years. Similarly, age 65 corresponds to the age of eligibility for full Social Security benefits for all classes over 65 in 1997 (the year studied), whereas in the future the eligibility age will be rising and this would make comparisons between classes in terms of retirement age more problematic.

A final consideration in the model is the possibility of cohort effects. That is, are donations related to a particular class in a way that is unrelated to the aging of the class? For example, did the class of 1930 donate differently at age 50 than the class of 1940 and, if so, was this because of different economic conditions (e.g., the performance of the stock market) when they turned 50 or for some inherent difference between the classes. Any inherent difference, which persists over time (or as the class ages), would be considered a cohort difference or effect. One could estimate these possible differences by introducing dummy variables for each class (e.g., Willemain, Goyal, Van Deven, and Thukral, 1994, use 90 class dummy variables) but this requires having data for multiple years of donations. In fact, in this same study the year of donation is accounted for by using 50 dummy variables. However, the use of dummy variables only detects differences, but does not explain them. Alternatively, Bristol (1991) succeeded in explaining year-to-year variations in alumni/ae donations on the basis of fluctuations in the stock market (in the year of donation).

In a similar vein, this paper will not introduce dummy variables for each class but will, instead, postulate that differences in classes are related to economic conditions in the year of graduation. If successful, statistically, these variables will serve to control for possible cohort differences and also explain the origin/reason for these differences. Specifically, economic conditions in the year of graduation will be introduced for each class and it is anticipated that unfavorable economic conditions (e.g., high unemployment) will have a negative impact on donations for the class. If true, it would imply that members of a class graduating in a year of high unemployment would make fewer donations over their lifetime, independent of what influence aging and retirement might have.

\section{Estimation Results}

The model(s) outlined will be estimated using data for donations made in 1997 to a small liberal college. There are 68 observations, one for each class from 1929 through 1996. Tables 1 and 2 provide estimations results for two separate equations, or models, which have different dependent variables that were previously defined. Specifically, the dependent variables are donor participation (PCDONOR) and average donation (AVGDON) in Tables 1 and 2, respectively. Each table is structured the same in that they each have five columns, or Models, that differ in terms of the independent variables included. Overall, the explanatory power (i.e., R squared) is greater for PCDONOR (Table 1) than for AVGDON (Table 2), for reasons that will be discussed later.

To begin the analysis of Table 1, it can be observed that REUNION is significant, as measured by its tvalue, and positive in all five Models (columns) in Table 1. This indicates that a larger percentage of a class donates in the year in which they have a 25 th or 50th reunion, which is consistent with previous studies that were discussed earlier. More important is the treatment of age. In Model 1 age (AGE) is used alone and it is positive, indicating a tendency for donor participation to increase with age, but its t-value is insignificant. However, when age squared is added, Model 2, both of the age variables (AGE and AGESQ) are significant. Their signs indicate a quadratic rela- 
tionship with a maximum at about 60 years of age. Rather than pursue raising age to more powers, and estimating a more complex polynomial relationship, as others have done (e.g., Bristol, 1990), this paper will introduce retirement (at age 65) for reasons delineated.

In an attempt to model retirement as an event that might alter the pattern of giving over a person's life, different specifications were tested. A dummy variable, at retirement, assumes a shift in giving that did not prove significant in the estimation process. Hence, to obtain a more continuous relationship (at the time of retirement) a variable, YRSRET, was introduced measuring the years (after 65) the class had been in retirement. This proved significant when used alone, Model 3, and was negative, indicating in decrease in donor participation after retirement. This is consistent with what was expected based on the economic theories of consumption reviewed in the beginning of the paper. A further refinement, or improvement (based on the increase in R squared), is obtained by adding Y RSRETSQ, the squared version of years retired. When taken together they indicate a quadratic relationship that peaks at 3.7 years (after retirement), which is again consistent with what economic theories of consumption would indicate. Actually, the peak in giving, as measured by PCDONOR (Table 1), is a little bit later in life (i.e., when the negative impact of the retirement variables (YRSRET and YRSRETSQ) outweighs the positive effect of the AGE coefficient (.006 in Model 4). This would be in the early seventies.

Taken together, the three age/retirement variables provide good overall explanatory power (i.e., the $\mathrm{R}$ squared is .897 for Model 4) and each individual independent variable is significant at the 1\% level (i.e., the t-values are all over 2.56). More importantly, the signs for the individual variables are what would be anticipated of the basis of economic

\begin{tabular}{|c|c|c|c|c|c|}
\hline \multicolumn{6}{|c|}{$\begin{array}{c}\text { Table 1 } \\
\text { Estimation Results (1929-96) } \\
\text { Dependent Variable: PCDONOR (donor percentage) }\end{array}$} \\
\hline $\begin{array}{l}\text { MODEL: } \\
\text { Independent } \\
\text { Variables: }\end{array}$ & 1 & 2 & \multicolumn{3}{|c|}{ (t-values in parentheses) } \\
\hline Constant & $\begin{array}{l}1.273 \\
(6.18)\end{array}$ & $\begin{array}{l}-.381 \\
(-4.28)\end{array}$ & $\begin{array}{l}.011 \\
(.28)\end{array}$ & $\begin{array}{l}.077 \\
(2.59)\end{array}$ & $\begin{array}{l}.131 \\
(3.96)\end{array}$ \\
\hline $\begin{array}{l}\text { REUNION (=1 if } \\
25 \text { or } 50 \mathrm{y}\end{array}$ & $\begin{array}{l}.195 \\
(2.24)\end{array}$ & $\begin{array}{c}.140 \\
(2.23)\end{array}$ & $\begin{array}{c}.148 \\
(2.63)\end{array}$ & $\begin{array}{l}.116 \\
(2.81)\end{array}$ & $\begin{array}{l}.108 \\
(2.77)\end{array}$ \\
\hline $\mathrm{AGE}^{1}$ (of class) & $\begin{array}{l}.0009 \\
(1.27)\end{array}$ & $\begin{array}{c}.028 \\
(8.04)\end{array}$ & $\begin{array}{c}.007 \\
(8.98)\end{array}$ & $\begin{array}{l}.006 \\
(8.56)\end{array}$ & $\begin{array}{c}.005 \\
(7.99)\end{array}$ \\
\hline $\begin{array}{l}\text { AGESQ (age } \\
\text { squared) }\end{array}$ & & $\begin{array}{l}-.0002 \\
(-7.86)\end{array}$ & & & \\
\hline $\begin{array}{l}\text { YRSRET }^{2} \text { (years } \\
\text { class retired) }\end{array}$ & & & $\begin{array}{c}-.002 \\
(-9.63)\end{array}$ & $\begin{array}{l}.010 \\
(2.25)\end{array}$ & $\begin{array}{c}.013 \\
(3.06)\end{array}$ \\
\hline $\begin{array}{l}\text { YRSRETSQ (years } \\
\text { retired squared) }\end{array}$ & & & & $\begin{array}{c}-.001 \\
(-7.53)\end{array}$ & $\begin{array}{c}-.001 \\
(-7.89)\end{array}$ \\
\hline $\begin{array}{l}\text { UNEMPRT (unem- } \\
\text { ployment rate, year } \\
\text { of graduation) }\end{array}$ & & & & & $\begin{array}{c}-.005 \\
(-3.09)\end{array}$ \\
\hline R Squared & .307 & .734 & .794 & .897 & .912 \\
\hline Sample Size & 68 & 68 & 68 & 68 & 68 \\
\hline
\end{tabular}

theory. Also, this model demonstrates that almost all (i.e., 89.7\%) of the variation in PCDONOR and be explained 
using age/retirement variables which are predictable. Thus, the model developed should be valuable in making forecasts of future class giving. More importantly, the results indicate aging, and particularly post-retirement changes, have a definite influence on the giving patterns of alumni/ae.

The final column (Model 5) in Table 5 represents an attempt to control for possible cohort effects in the data by introducing independent variables measuring economic conditions in the year in which a class graduated. While other economic conditions variables were tried (e.g., interest rates, inflation rate, economic growth (in GDP), and a war/peace dummy variable), they proved less significant than unemployment (UNEMPRT), in part because of multicollinearity problems. In any case, unemployment is the most intuitive and it is both significant and has the correct sign, negative. The significance indicates some success in controlling for cohort effects and the negative sign is what was anticipated on the basis of economics. Another advantage of using UNEMPRT is that it, like the other independent variables, is predictable and this is desirable from a forecasting standpoint.

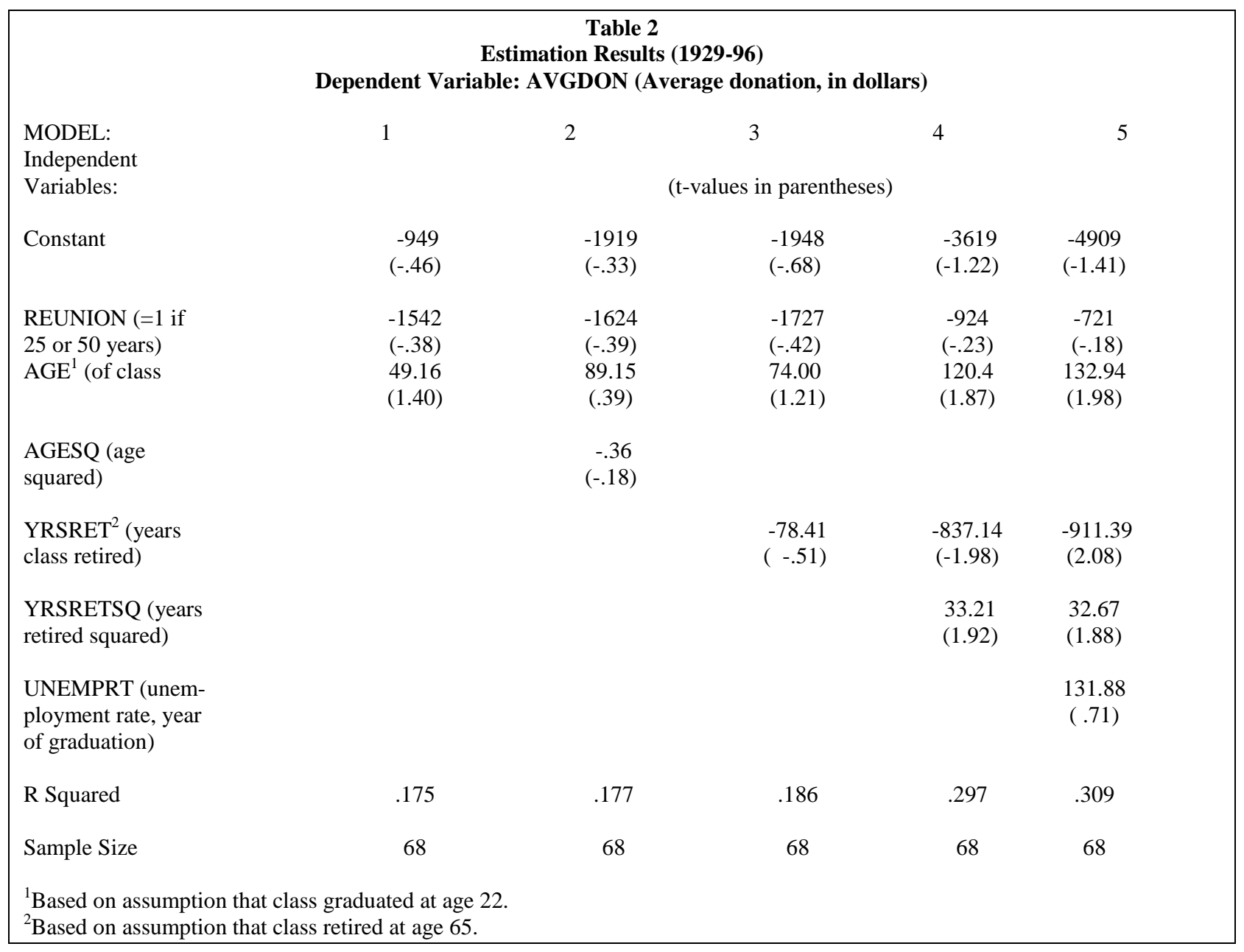

While the results in Table 1 are encouraging, when the same approach is used for the other dependent variable, AVGDON, in Table 2, the explanatory power is considerably reduced. However, there are similarities between Tables 1 and 2. For example, in Table 2 the R squared improves going from Model 1 through Model 5, but not nearly as dramatically as it did in Table 1 . Since most of the independent variables are only marginally significant or insignificant, no attempt will be made to carefully interpret each coefficient, as was done in Table 1 . Most of the difficulty in estimating AVGDON, the dependent variable in Table 2, is that there are some years (classes), 
which have very large values because of a few extremely large individual donations. There are several alternative ways to try to ameliorate this problem. One would be to eliminate the classes with the large (outlier) values, but this loses information. The approach that will be taken is to use moving averages for the dependent variable(s), as presented in Table 3. Another possibility, which will be tried in the future, is to breakdown donors into groups on the basis of the size of their gift (e.g., have as the dependent variable(s) the percentage of the class that are low, medium or high donors). By so doing it would isolate the influence of large gifts to a homogeneous grouping of donors.

\begin{tabular}{|c|c|c|c|c|}
\hline \multicolumn{5}{|c|}{$\begin{array}{c}\text { Table 3 } \\
\text { Estimation Results (1929-96) }\end{array}$} \\
\hline $\begin{array}{l}\text { Dependent Variable } \\
\text { Moving Average: }\end{array}$ & $\begin{array}{l}\text { PCDONOR } \\
\text { (3-year) }\end{array}$ & $\begin{array}{l}\text { PCDONOR } \\
\text { (5-year ) }\end{array}$ & $\begin{array}{c}\text { AVGDON } \\
\text { (5-year) }\end{array}$ & $\begin{array}{l}\text { TOTDON } \\
\text { (total donations, } \\
\text { in dollars) }\end{array}$ \\
\hline $\begin{array}{l}\text { MODEL: } \\
\text { Independent }\end{array}$ & 1 & 2 & 3 & 4 \\
\hline Variables: & \multicolumn{4}{|c|}{ (t-values in parentheses) } \\
\hline constant & $\begin{array}{l}.122 \\
(4.90)\end{array}$ & $\begin{array}{l}.124 \\
(5.79)\end{array}$ & $\begin{array}{l}-3978 \\
(-2.89)\end{array}$ & $\begin{array}{c}-305171 \\
(-.81)\end{array}$ \\
\hline $\begin{array}{l}\text { REUNION }(=1 \text { if } \\
25 \text { or } 50 \text { years) } \\
\text { AGE }^{1} \text { (of class) }\end{array}$ & $\begin{array}{c}-.01 \\
(-.50) \\
.0057 \\
(12.01)\end{array}$ & $\begin{array}{c}.0008 \\
(.03) \\
.006 \\
(14.33)\end{array}$ & $\begin{array}{c}-987.19 \\
(-.61) \\
104.68 \\
(3.94\end{array}$ & $\begin{array}{c}-107706 \\
(-.24) \\
11205 \\
(1.55)\end{array}$ \\
\hline $\begin{array}{l}\text { YRSRET }^{2} \text { (years } \\
\text { class retired) }\end{array}$ & $\begin{array}{l}.0015 \\
(.08)\end{array}$ & $\begin{array}{r}-.005 \\
(-1.86)\end{array}$ & $\begin{array}{r}-619.54 \\
(-3.57)\end{array}$ & $\begin{array}{l}-70925 \\
(-1.50)\end{array}$ \\
\hline $\begin{array}{l}\text { YRSRETSQ (years } \\
\text { retired squared) }\end{array}$ & $\begin{array}{c}-.001 \\
(-7.71)\end{array}$ & $\begin{array}{l}-.0007 \\
(-6.52)\end{array}$ & $\begin{array}{l}20.66 \\
(3.01)\end{array}$ & $\begin{array}{c}1828.5 \\
(.97)\end{array}$ \\
\hline $\begin{array}{l}\text { UNEMPRT (unem- } \\
\text { ployment rate, year } \\
\text { of graduation) }\end{array}$ & $\begin{array}{l}-.006 \\
(-4.34)\end{array}$ & $\begin{array}{l}-.006 \\
(-5.46)\end{array}$ & $\begin{array}{r}181.76 \\
(2.48)\end{array}$ & $\begin{array}{l}3592 \\
(.18)\end{array}$ \\
\hline R Squared & .950 & .963 & .567 & .235 \\
\hline Sample Size & 68 & 68 & 68 & 68 \\
\hline
\end{tabular}

Table 3, unlike Tables 1 and 2, uses the same set of independent variables (i.e., Model 5 in Tables 1 and 2) for alternative specifications of the dependent variable(s). Primarily, this table is designed to investigate the effects of using moving averages for the dependent variable(s). As discussed, moving averages are one method of smoothing the influence of outlier observations (of the dependent variable), which was a problem in Table 2. Another advantage is with respect to the older classes, which have fewer and fewer alumni/ae of record, and, as a result, the values of the dependent variables are more volatile for these classes. It should be noted that a decision was made to use only classes back to 1929 because earlier classes had dramatically smaller alumni/ae of record. On the other hand, the model(s) were tested using only classes after 1939 and similar results were obtained. In any case, by using moving averages, the series is smoothed for the earliest classes as well as for the outlier classes (i.e., large values for AVGDON). While both 3 and 5-year moving averages were tried, better results were obtained for the 5-year moving average (see Model 2 (5-year) and Model 1 (3-year) in Table 3). Therefore, both dependent variables (PCDONOR and AVGDON) were estimated using a 5-year moving average. 
One consequence of using moving averages is that the significance of REUNION is diminished, as would be expected. The AGE variable is positive, as it was in earlier results, but more significant, especially for the AVGDON model. In fact, the most dramatic change from using moving averages is for the AVGDON model in that the R squared increases from .309 (Model 5 in Table 2) to .567 (Model 3 in Table 3), whereas the increase in $R$ squared is smaller for PCDONOR (i.e., from .912 for Model 5 in Table 1 to .963 for Model 2 in Table 3).

The results for individual independent variables are comparable to those obtained in Table 1, most notably that the retirement variables are significant again in Table 3 (Model 2) and indicate a peak in participation shortly after retirement. On the other hand, the AVGDON variable (i.e., Model 3 in Table 3) indicates somewhat the opposite pattern after retirement. That is, the signs of the variables YRSRET (positive) and YRSRETSQ (negative) indicate that the size of donations falls after retirement, reaches a minimum (about 15 years after retirement, or age 80), and then increases again. Actually, the minimum may come a few years earlier when the effect of AGE (i.e., an increase of 104.68 each year) is considered. Most encouraging is the fact that both the retirement variables are more significant in Table 3 (for AVGDON) than they were in Table 2. As will be discussed, the indication that retirement has opposite effects on PCDONOR and AVGDON, in terms of there being a maximum for one and a minimum for the other, suggests that forecasting donations after retirement would require consideration of both components, PCDONOR and AVGDON.

To further demonstrate the need for estimating PCDONOR and AVGDON separately, an equation was estimated (Model 4 in Table3) using total dollar donations of each class (TOTDON) as a dependent variable. The results are much worse in terms of overall explanation (i.e., the $\mathrm{R}$ squared is only .235) and all independent variables are insignificant at the 5\% level. In contrast, the separate model(s) approach achieved much better statistical results and it is easier to understand. The connection between using TOTDON and the dependent variables modeled is that, for any class, TOTDON would be the product of PCDONOR, AVGDON, and the number of alumni/ae of record. While this paper has not offered a model to explain/predict the number of alumni/ae of record, this could be done either using national cohort survival tables, for each age, or by estimating survival rates for the classes on the basis of changes in the number of alumni/ae of record for different years of donation. For example, the alumni/ae of record in 1996 for the Class of 1950 divided by the number of alumni/ae of record in 1997 for the Class of 1950 could be used to estimate the survival rate for 68 year old alumni/ae (assuming 1950 graduates would be 68 in 1996 if they graduated at age 22).

Finally, the variable for economic conditions (in the year of graduation), UNEMPRT, is negative for PCDONOR, as it was in Table 1, for reasons previously discussed. On the other hand, this variable is positive for AVGDON, indicating that larger average gifts are given by the classes that graduated in years with poor economic conditions (i.e., high unemployment). Together, these results suggest that while fewer alumni/ae succeeded if they graduated in a year of high unemployment, those who did were very successful and this results in higher average donations for the class. While such interpretations are mostly conjecture, the significance of UNEMPRT in both equations (i.e., Models 2 and 3) in Table 3 does serve to control for possible cohort effects in the data, as was earlier discussed.

\section{Discussion}

Most studies of alumni/ae altruism have had forecasting as their motivation and, consequently, the independent variables have been selected on a somewhat pragmatic basis. In particular, age has often been used in complex ways (e.g., high order polynomials or a series of dummy variables) that are statistically significant but do not lend themselves to simple interpretation. This paper, on the other hand, has tried to introduce age and to suggest that it will influence altruism based on economic theories of consumption. Moreover, it postulates that there will be changes in giving associated with retirement (age) and that these are separate from the general effect of the aging process that begins with graduation. The estimation results, in general, support the conclusion that, in fact, aging/retirement have much to do with the year-to-year changes in alumni/ae giving that will occur over the life of a graduating class. 
Specifically, it is found that while donor participation peaks about five years after retirement, the average size of gifts falls after retirement and then begins to rise after age 80 . These somewhat complex patterns of giving for elderly alumni/ae suggest that those raising donations for such populations is a task that may require changes in emphasis as the classes age. While most other analyses of alumni/ae giving have stressed the importance of reunions, this paper has not, in part by using moving averages. By so doing, the emphasis has been focused on the aging/retirement variables. Likewise, the specification of the donor participation variable (i.e., using alumni/ae of record, rather than size of the graduating class, as the denominator) was done so that mortality would not influence the effect of aging on giving in the later life of a class. Altogether, the model(s) developed and estimated were intended to discover the linkage between aging/retirement and alumni/ae altruism.

While not the primary purpose of the paper, an attempt was made to develop an approach that would lend itself to forecasting. In the future this will be done. Also, the problems resulting from very large donations for a few classes will be analyzed in different ways. In particular, by dividing the donors into more homogeneous groups on the basis of the size of their donation it should be possible to isolate the large donors and better understand them.

A final thought is with respect to results obtained for the variable measuring unemployment in the year of graduation. While the main reason for using this was to control for any possible cohort effects, the significance of it requires that it's meaning be considered. At least in terms of donor participation, the indication is that having graduated in a year of high unemployment will negatively effect alumni/ae giving throughout one's life. Given the assumption that altruism is positively related to income, the results suggest there is an economic determinism to one's life that is forged by the good or bad economic conditions that exist at the time of graduation. If true, such an outcome might be somewhat disconcerting to those who believe in capitalism and the "Protestant work ethic."

In any case, the paper has hopefully shown that our understanding of alumni/ae altruism can be increased by consideration of the importance of the aging process and, in particular, changes that occur after retirement.

\section{References}

1. Bristol, R. B., (1990), "The Life Cycle of Alumni Donations," The Review of Higher Education, 13, 503518.

2. Bristol, R. B., (1991), "How Much Will Alumni Give in the Future?," Planning for Higher Education, 20, $1-12$.

3. $\quad$ Britto, M., and Oliver, R. M., (1986), "Forecasting Donors and Donations," Journal of Forecasting, 5, 3955.

4. Bruggink, T. H., and Siddiqui, K., (1995), “An Econometric Model of Alumni Giving: A Case Study for a Liberal Arts College," American Economist, 39, 53-60.

5. Grant, J. H., and Lindauer, D. L., (1986), "The Economics of Charity: Life Cycle Patterns of Alumnae Contributions," Eastern Economic Journal, 2, 129-141.

6. Lindahl, W. E., and Winship, C., (1992), "Predictive Models for Annual Fundraising and Major Gift Fundraising," Nonprofit Management \& Leadership, 3, 43-64.

7. Okunade, A. A., Wunnava, P. V., and Walsh, R., (1994), "Charitable Giving of Alumni: Micro-data Evidence from a Large Public University," American Journal of Economics and Sociology, 53, 73-84.

8. Okunade, A. A. (1996), "Graduate School Alumni Donations to Academic Funds: Micro-data Evidence," American_Journal of Economics and Sociology, 55, 213-229.

9. Taylor, A. L., and Martin, J. C., (1995), "Characteristics of Alumni Donors and Nondonors at a Research I, Public University," Research in Higher Education, 36, 283-302.

10. Willemain, T. R., Goyal, A., Van Deven, M., and Thukral, I. S. (1994), "Alumni Giving: The Influences of Reunion, Class, and Year," Research in Higher Education, 35, 609-629.

Notes 